\title{
Zusammenfassung Teil II
}

Dieser Leitfaden hat ein praxisorientiertes Vorgehensmodell vorgestellt, mit dem Unternehmen Geschäftsmodell-Innovationen erfolgreich auf den Weg bringen können. Das Vorgehensmodell ist in einen schrittweisen Prozess gegliedert, der Unternehmen als Methodenbaukasten von der ersten Idee bis zur Realisierung begleitet. Das Vorgehensmodell setzt sich aus fünf Schritten zusammen. Der erste Schritt umfasst die Vorbereitung und die Analyse des Umfelds des Unternehmens. Dadurch wird eine geeignete Ausgangsbasis für die Ideenfindung in einem interdisziplinären Team gelegt. Die Ideenfindung in Schritt Zwei erfolgt sowohl mittels bewährter Kreativitätsmethoden als auch mithilfe der Geschäftsmodellmuster entlang der Wertschöpfungskette nach Porter. Im dritten Schritt, der Ideenbewertung, werden die Ideen evaluiert, um Erfolg versprechende Geschäftsmodell-Ideen herauszufiltern. Für die selektierten Ideen werden in Schritt Vier detaillierte Konzepte erstellt und die Implementierung geplant. Den letzten Schritt bildet die Überführung dieser Konzepte in Projekte zu Realisierung des Geschäftsmodells in Form der Markteinführung. 